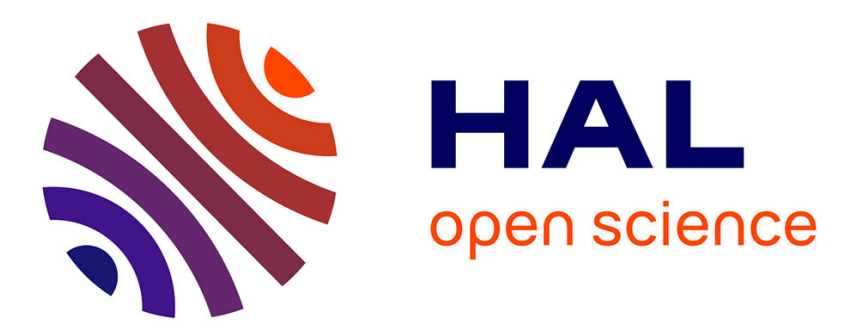

\title{
Strong enhancement of two-photon absorption properties in synergic 'semi-disconnected' multiporphyrin assemblies designed for combined imaging and photodynamic therapy.
}

Olivier Mongin, Muniappan Sankar, Marina Charlot, Youssef Mir, Mireille Blanchard-Desce

\section{To cite this version:}

Olivier Mongin, Muniappan Sankar, Marina Charlot, Youssef Mir, Mireille Blanchard-Desce. Strong enhancement of two-photon absorption properties in synergic 'semi-disconnected' multiporphyrin assemblies designed for combined imaging and photodynamic therapy.. Tetrahedron Letters, 2013, 54 (48), pp.6474-6478. 10.1016/j.tetlet.2013.09.076 . hal-00916343

\section{HAL Id: hal-00916343 \\ https://hal.science/hal-00916343}

Submitted on 10 Dec 2013

HAL is a multi-disciplinary open access archive for the deposit and dissemination of scientific research documents, whether they are published or not. The documents may come from teaching and research institutions in France or abroad, or from public or private research centers.
L'archive ouverte pluridisciplinaire HAL, est destinée au dépôt et à la diffusion de documents scientifiques de niveau recherche, publiés ou non, émanant des établissements d'enseignement et de recherche français ou étrangers, des laboratoires publics ou privés. 


\section{Strong enhancement of two-photon absorption properties in synergic "semi-disconnected" multiporphyrin assemblies designed for combined imaging and photodynamic therapy.}

Olivier Mongin, ${ }^{a, b}$ Muniappan Sankar, ${ }^{a}$ Marina Charlot, ${ }^{a}$ Youssef Mir $^{a}$ and Mireille Blanchard-Desce* ${ }^{* a, c}$

${ }^{a}$ Chimie et Photonique Moléculaires (CNRS UMR 6510), Université de Rennes 1, Campus de Beaulieu, F-35042 Rennes Cedex, France

${ }^{b}$ Institut des Sciences Chimiques de Rennes (CNRS UMR 6226), Université de Rennes 1, Campus de Beaulieu, F-35042 Rennes Cedex, France

${ }^{c}$ Univ. Bordeaux, Institut des Sciences Moléculaires (CNRS UMR 5255), 351 Cours de la Libération, F-33405 Talence Cedex, France

* Corresponding author. Tel.: (+33) 5-40-00-67-32; fax: (+33) 5-40-00-69-94; e-mail: m.blanchard-desce@ism.u-bordeaux1.fr

Abstract :

The synthesis and photophysical properties of new multiporphyrin assemblies are described. Their design, based on a smooth electronic disconnection between two-photon absorbing (2PA) octupolar or quadrupolar cores and the peripheral porphyrins, leads to a major increase in (non-resonant) 2PA responses in the NIR, while fully retaining the fluorescence and photosensitization properties of isolated porphyrins. This approach, which involves electronic coupling of semi-disconnected moieties in the higher excited states of the synergic systems, is of interest to fully benefit from the advantages of selective 2PA for application in combined two-photon high resolution imaging and photodynamic therapy.

Keywords:

Sonogashira coupling

Porphyrin

Photosensitizer

Singlet oxygen

Fluorescence

Two-photon absorption (2PA) 
Photodynamic therapy (PDT) is a medical technique used in oncology for the treatment of several tumours as well as in ophthalmology especially in the treatment of age-related macular degeneration (ARMD). ${ }^{1,2}$ The use of a two-photon (2P) excitation offers new perspectives for PDT, especially for the treatment of small areas, such as small solid tumours. Indeed two-photon absorption (2PA) offers several advantages, which includes the ability for highly selective excitation in biological media and intrinsic three-dimensional resolution as well as increased penetration depth in tissues. ${ }^{3}$ This however calls for the use of optimized 2P photosensitizers that should combine large 2PA cross-sections in the biological spectral window (700-1100 nm) and high singlet oxygen quantum yields (or ROS production). Most of the photosensitizers currently used clinically or in clinical trials are porphyrin derivatives, such as porfimer sodium (Photofrin) and verteporfin (Visudyne). These compounds exhibit high singlet oxygen quantum yields but low 2PA cross sections (10 GM and $50 \mathrm{GM}$, respectively) in the $\mathrm{NIR}^{4}$ as model tetraphenylporphine (TPP, $12 \mathrm{GM}){ }^{5}$ _ENREF 8 Dramatic enhancement of the $2 \mathrm{PA}$ crosssections can be achieved in porphyrinoids, ${ }^{6}$ or expanded porphyrins, ${ }^{7}$ in conjugated porphyrin dimers, trimers and oligomers, ${ }^{8}$ planarized fused or bridged porphyrins ${ }^{9}$ or supramolecular assemblies. ${ }^{8 a, 10}$ The extension of the $\pi$-conjugated system involves the porphyrin or porphyrinoid macrocycles thus leading to major modification of their photophysical properties: a marked broadening and red-shift of the Q-bands is observed resulting in residual one-photon absorption (1PA) overlapping with the 2PA band located in the NIR region. This promotes resonance enhancement of the 2PA band leading to giant 2PA cross-sections. Other consequences are however possible loss of $3 \mathrm{D}$ resolution (due to concomitant 1PA) and weakening of fluorescence and photosensitizing properties. Nevertheless biphotonic photosensitizers that maintain significant fluorescence are highly desirable to allow in vivo monitoring and subsequent localized irradiation.

Here we describe our efforts towards the design of porphyrin-based $2 \mathrm{P}$ photosensitizers exhibiting large 2PA in the NIR - with no 1PA - and retaining the fluorescence as well as the excellent photosensitization properties of the porphyrin moiety. Dendritic antenna systems based on resonant energy transfer (FRET) from peripheral 2P absorbers towards a single porphyrin core have been previously designed. ${ }^{11}$ In contrast, our strategy is based on multiporphyrin assemblies with a weak conjugation between a central 2PA unit and peripheral porphyrins. A smooth electronic disconnection between the porphyrin moieties and the conjugated $\pi$-system is ensured by deviation from planarity (Figure 1), so as to retain some of the photochemical features of native porphyrins (in particular singlet oxygen production and fluorescence).

To achieve this goal, we chose meso-tetraarylporphyrin derivatives, where a phenyl ring in meso position prevents porphyrins to be coplanar with the 2PA unit, due to steric effects ${ }^{12}$ (Figure 1). Four multiporphyrin assemblies $(\mathbf{1} \mathbf{a}, \mathbf{1} \mathbf{b}, \mathbf{2}, \mathbf{3})$ were synthesized. Inspired by our seminal work on the design of conjugated quadrupolar, octupolar chromophores for $2 \mathrm{PA},{ }^{13}$ we selected fluorene and triphenylamine as cores in dumbbell-like or three-branched derivatives, and phenyleneethynylene or fluorenylene-ethynylene as connectors to the peripheral porphyrin units (Figure 1). Derivatives $\mathbf{2}$ and $\mathbf{3}$ bear pyridyl and triethyleneglycol substituents which should improve their hydrophilicity and biocompatibility. It should be stressed here that pyridines might be further quaternarized. 


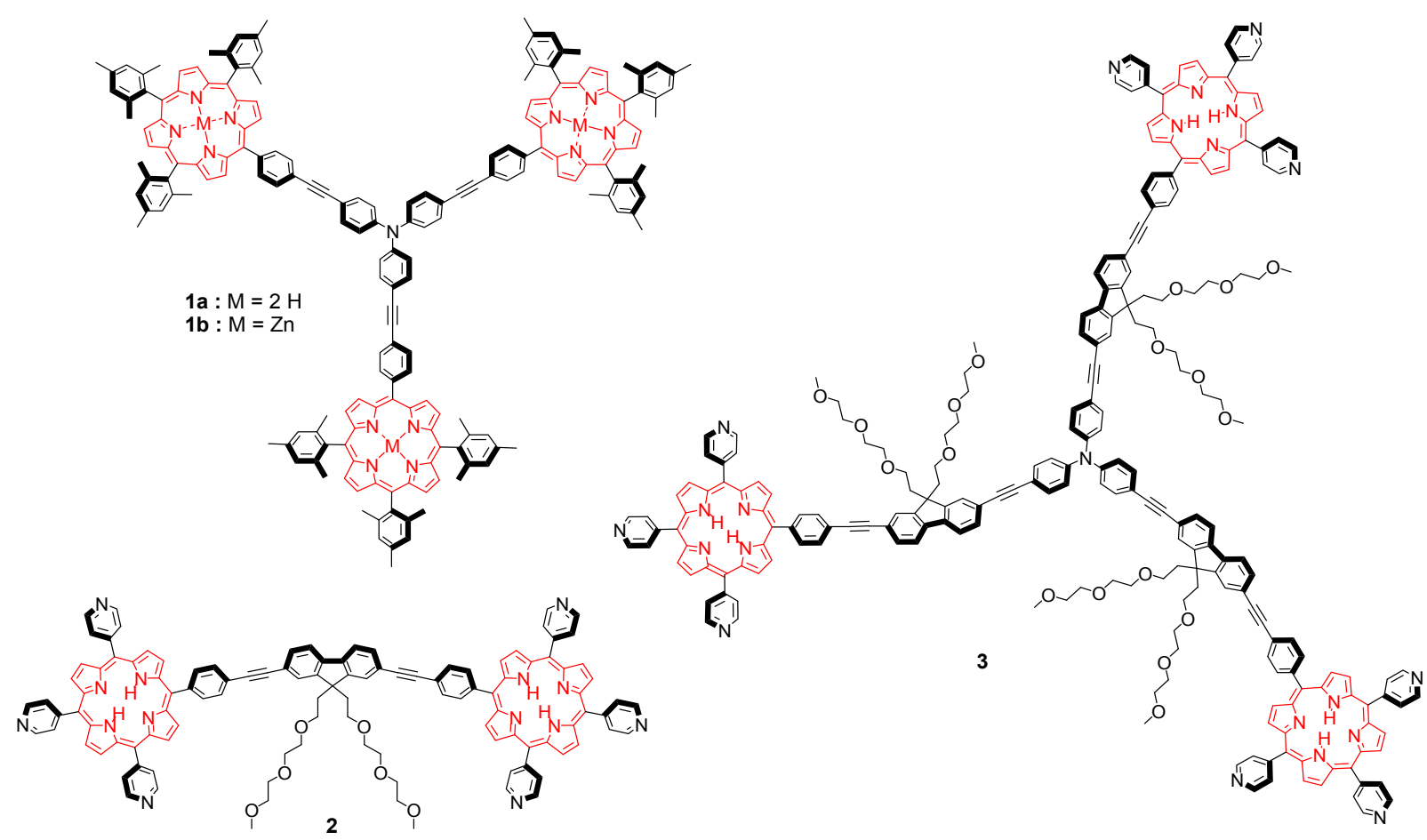

Figure 1. Chemical structures of "electronically disconnected" porphyrin dimers and trimers.

Porphyrin trimer 1a was obtained from the threefold Pd-catalyzed cross-coupling reaction between ethynyl porphyrin $4^{14}$ and triodotriphenylamine 5. $^{13 a}$ Its metalation with zinc acetate afforded zinc porphyrin trimer $\mathbf{1 b}$ (Scheme 1).

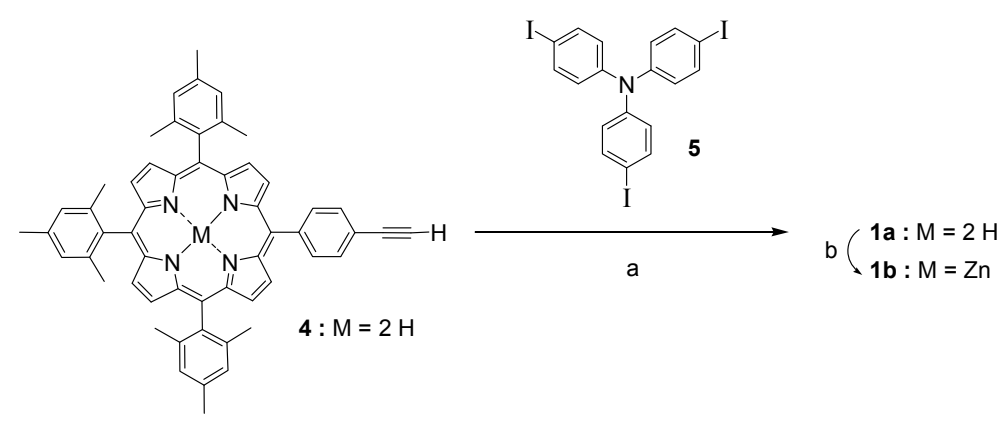

Scheme 1. Reagents and conditions (a) $\mathrm{Pd}_{2} \mathrm{dba}_{3}, \mathrm{AsPh}_{3}, \mathrm{DMF} / \mathrm{Et}_{3} \mathrm{~N}, 40{ }^{\circ} \mathrm{C}, 15 \mathrm{~h}(47 \%)$. (b) $\mathrm{Zn}(\mathrm{OAc})_{2} \cdot 2 \mathrm{H}_{2} \mathrm{O}$, $\mathrm{CHCl}_{3} / \mathrm{MeOH}$, reflux, $1 \mathrm{~h}(82 \%)$.

Porphyrin dimer 2 was synthesized in a multistep sequence from 2,7-diiodofluorene $\mathbf{6 b} .{ }^{15}$ Dialkylation of fluorene $\mathbf{6 b}$ with [2-[2-(2-methoxyethoxy)ethoxy] ethoxy]p-toluenesulfonate in the presence of $\mathrm{NaOH}$ and tetrabutylammonium bromide afforded 7a. The double Sonogashira coupling of diiodo derivative 7a with 2-methyl-3-butyn-2-ol afforded 7c, which was deprotected with $\mathrm{NaOH}$ to afford diethynylfluorene $7 \mathbf{d}$. The double coupling of the latter with bromoporphyrin derivative $\mathbf{8}^{16}$ gave porphyrin dimer 2 (Scheme 2). The synthesis of 
extended porphyrin trimer 3 started also from diiodofluorene derivatives $\mathbf{6 b}$ and $7 \mathbf{a}$. The latter compound was desymmetrized by reaction with a single equivalent of 2-methyl-3-butyn-2-ol, affording monoiodo derivative $\mathbf{7 b}$. The Sonogashira reaction of triethynyltriphenylamine core $9^{13 a}$ with three equivalents of $7 \mathbf{b}$ led to extended core $10 a$, the protecting groups of which were cleaved with $\mathrm{NaOH}$, giving triethynyl derivative 10b. Extended porphyrin trimer 3 was finally obtained from the threefold palladium $(0)$ catalyzed reaction of $\mathbf{1 0 b}$ with three equivalents of bromoporphyrin 8 (Scheme 2).

The photophysical characteristics (including one-photon absorption, luminescence, singlet oxygen generation and two-photon absorption) of the new porphyrin assemblies are gathered in Table 1. As shown in Figures 2 and 3, all compounds exhibit intense absorption bands in the UV and visible regions. Absorption spectra of the free-base multiporphyrin assemblies $(\mathbf{1 a}, \mathbf{2}, \mathbf{3})$ closely resemble that of TPP, ${ }^{17}$ the characteristic $\mathrm{Q}$ bands and Soret band being unaffected. This reveals that the lower excited states are preserved and localized on the porphyrin peripheral units, suggesting that no major electronic coupling between the conjugated core and the peripheral porphyrins occurs in these states (Figure 2, left). The absorption spectrum of trimer $\mathbf{1 b}$ is also typical of zinc tetraarylporphyrin complexes (See Supporting Information, Figure S1). No bathochromic shift of the Q bands is observed thus preserving full transparency in the NIR.

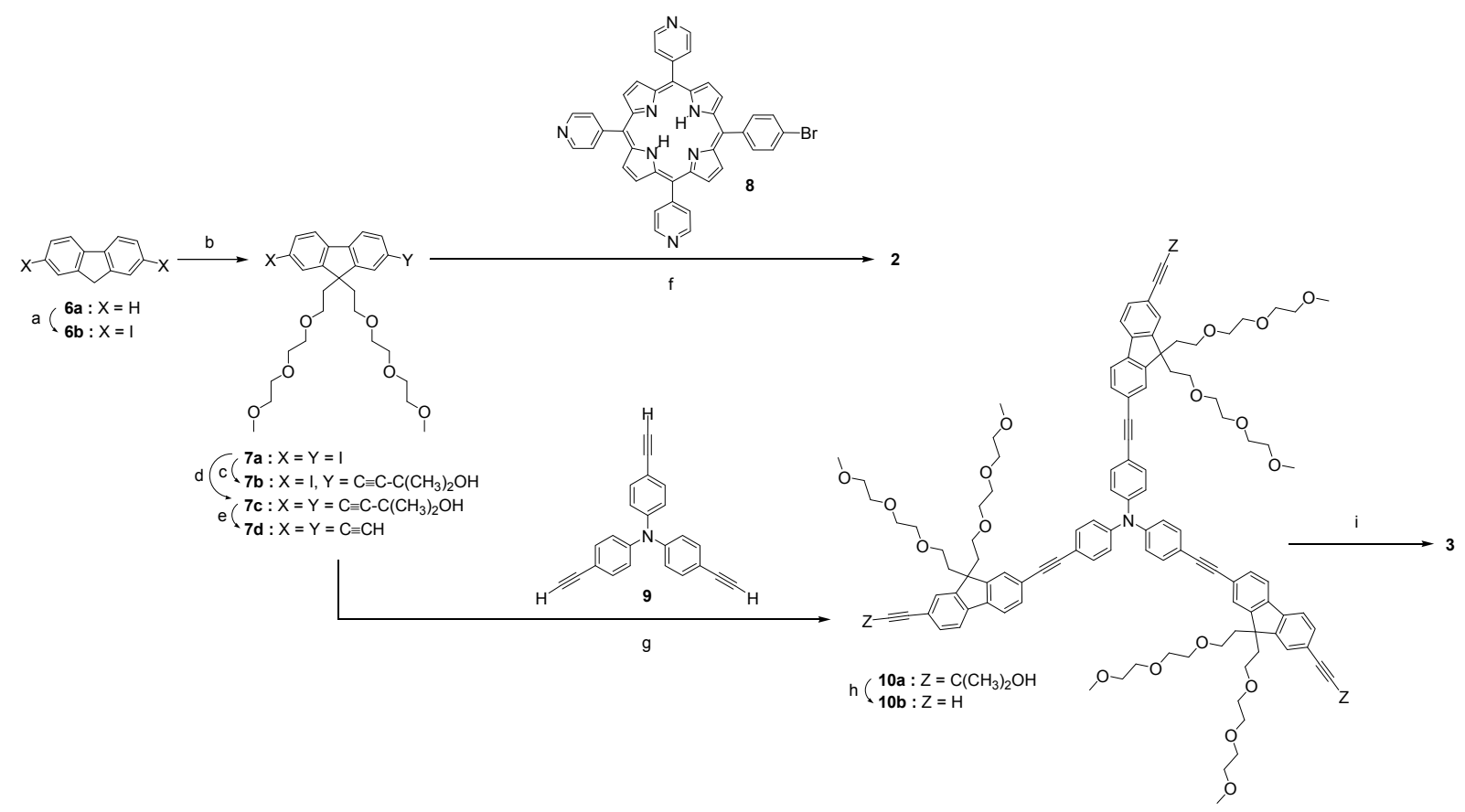

Scheme 2. Reagents and conditions (a) $\mathrm{I}_{2}, \mathrm{H}_{5} \mathrm{IO}_{6}, \mathrm{AcOH}, \mathrm{H}_{2} \mathrm{SO}_{4}, \mathrm{H}_{2} \mathrm{O}, 75{ }^{\circ} \mathrm{C}, 2 \mathrm{~h}$ (68\%). (b) $\mathrm{CH}_{3}\left(\mathrm{OCH}_{2} \mathrm{CH}_{2}\right)_{3} \mathrm{OTs}, \mathrm{NBu}_{4} \mathrm{Br}, \mathrm{KOH}, 75{ }^{\circ} \mathrm{C}$, 8h (59\%). (c) 2-methyl-3-butyn-2-ol (1 equiv), $\mathrm{Pd}\left(\mathrm{PPh}_{3}\right)_{2} \mathrm{Cl}_{2}, \mathrm{CuI}$, toluene/ $\mathrm{Et}_{3} \mathrm{~N}, 40{ }^{\circ} \mathrm{C}, 16 \mathrm{~h}(29 \%)$. (d) 2-methyl-3-butyn-2-ol (3 equiv), $\mathrm{Pd}\left(\mathrm{PPh}_{3}\right)_{2} \mathrm{Cl}_{2}, \mathrm{CuI}$, toluene/Et ${ }_{3} \mathrm{~N}, 40{ }^{\circ} \mathrm{C}$,

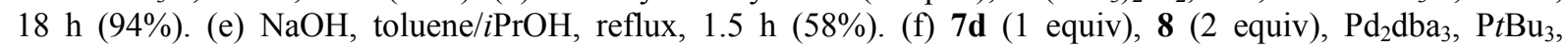
$\mathrm{DMF} / \mathrm{Et}_{3} \mathrm{~N}, 90^{\circ} \mathrm{C}, 5 \mathrm{~h}(27 \%)$. (g) $7 \mathbf{b}$ (4 equiv), 9 (1 equiv), $\mathrm{Pd}\left(\mathrm{PPh}_{3}\right)_{2} \mathrm{Cl}_{2}, \mathrm{CuI}$, toluene/ $\mathrm{Et}_{3} \mathrm{~N}, 40{ }^{\circ} \mathrm{C}, 60 \mathrm{~h}(43 \%)$. (h) $\mathrm{NaOH}$, toluene/iPrOH, reflux, $1 \mathrm{~h}(51 \%)$. (i) 8 (3 equiv), $10 b$ ( 1 equiv), $\mathrm{Pd}_{2} \mathrm{dba}_{3}, \mathrm{P} t \mathrm{Bu}_{3}, \mathrm{DMF} / \mathrm{Et}_{3} \mathrm{~N}, 90^{\circ} \mathrm{C}, 5$ h $(14 \%)$. 

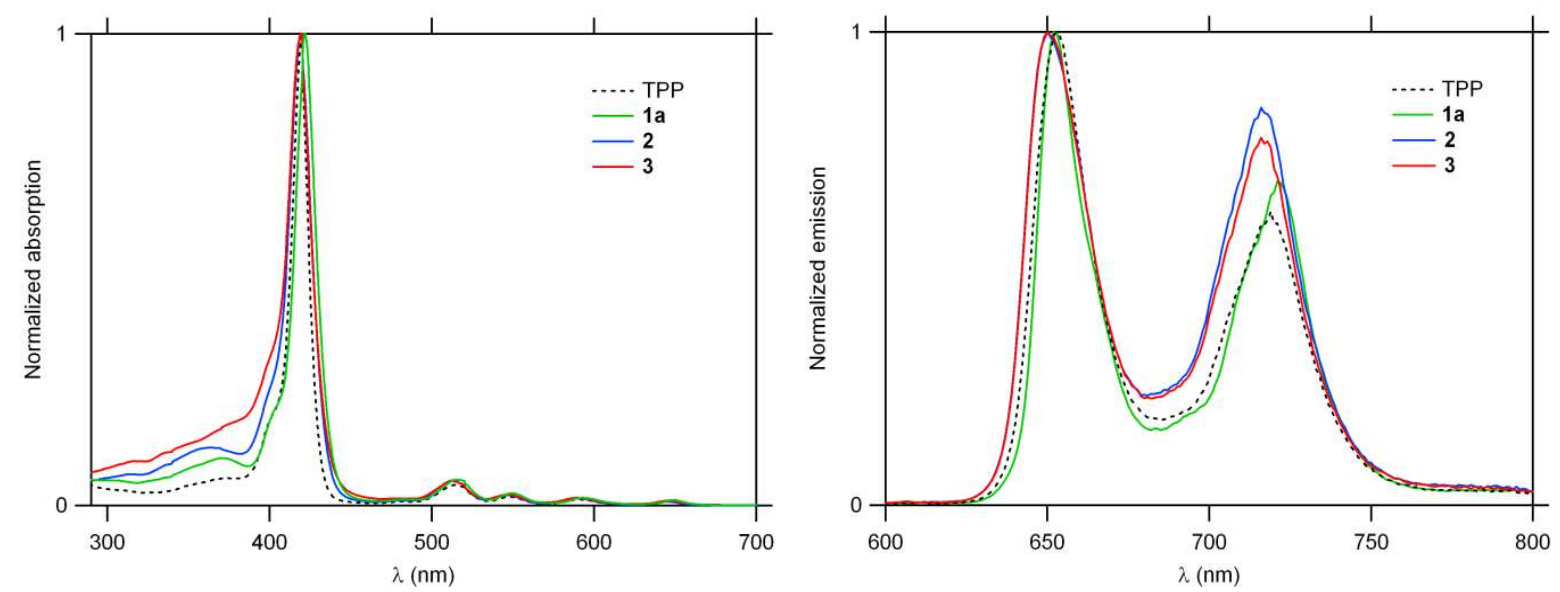

Figure 2. Absorption (left) and emission (right) spectra of free-base porphyrin derivatives $\mathbf{1 a}, \mathbf{2}$ and $\mathbf{3}$ and comparison with TPP.

Table 1 Photophysical data of porphyrin assemblies and model TPP.

\begin{tabular}{lllllllllll}
\hline Compd & $\begin{array}{l}\lambda_{\mathrm{abs}}(\mathrm{core}) \\
(\mathrm{nm})\end{array}$ & $\begin{array}{l}\lambda_{\mathrm{abs}}(\text { Soret }) \\
(\mathrm{nm})\end{array}$ & $\begin{array}{l}\varepsilon_{\max } \\
\left(\mathrm{M}^{-1} \cdot \mathrm{cm}^{-1}\right)\end{array}$ & $\begin{array}{l}\lambda_{\text {abs }}(\mathrm{Q} \text { bands }) \\
(\mathrm{nm})\end{array}$ & $\begin{array}{l}\lambda_{\mathrm{em}}{ }^{\max } \\
(\mathrm{nm})\end{array}$ & $\Phi_{\mathrm{F}}{ }^{c}$ & $\Phi_{\Delta}{ }^{d}$ & $\begin{array}{l}\lambda_{2 \mathrm{PA}}{ }^{\max } \\
(\mathrm{nm})\end{array}$ & $\begin{array}{l}\sigma_{2}{ }^{\max } \\
(\mathrm{GM})\end{array}$ & $\begin{array}{c}\text { Enhancement } \\
\text { factor }^{e}\end{array}$ \\
\hline $\mathbf{1 a}^{a}$ & 371 & 422 & $1.210^{6}$ & $515,549,593,649$ & 652,721 & 0.12 & 0.66 & 810 & 470 & 13 \\
$\mathbf{1 b}^{a}$ & 362 & 425 & $1.510^{6}$ & 551,589 & 605,648 & 0.05 & 0.70 & 800 & 390 & 11 \\
$\mathbf{2}^{b}$ & 364 & 420 & $7.810^{5}$ & $513,547,589,645$ & 650,717 & 0.09 & $0.74^{a}$ & 790 & 480 & 20 \\
$\mathbf{3}^{b}$ & $378(\mathrm{sh})$ & 419 & $1.210^{6}$ & $513,547,589,645$ & 650,717 & 0.08 & $0.72^{a}$ & 790 & 1360 & 38 \\
$\mathbf{T P P}^{a}$ & - & 420 & $4.410^{5 f}$ & $514,548,591,649$ & 653,719 & $0.11^{g}$ & $0.70^{h}$ & 790 & $12^{i}$ & - \\
\hline
\end{tabular}

${ }^{a}$ In toluene. ${ }^{b}$ In THF. ${ }^{c}$ Fluorescence quantum yield determined relative to TPP in toluene. ${ }^{d}$ Singlet oxygen quantum yield determined in toluene relative to TPP in toluene. ${ }^{e}$ Ratio between the maximum 2PA cross section of each compound (normalized by the number of porphyrins in the assembly) and the 2PA cross section of TPP at $790 \mathrm{~nm} .{ }^{f}$ Data from lit. ${ }^{17} \mathrm{~g}$ Data from lit. ${ }^{18}{ }^{h}$ Data from lit. ${ }^{19}{ }^{i}$ Data from lit. ${ }^{5}$

In contrast, the presence of the conjugated core moiety promotes the rise of a new absorption band in the near-UV region to the blue side of the Soret band (Table 1), whose intensity increases with increasing size of the core (Figure 1). This band reveals the emergence of higher excited states that modify the excitation behavior of the assembly as compared to TPP. The photochemical properties of multiporphyrin assemblies 1-3 are similar to that of TPP, in agreement with a lower excited state mostly localized on peripheral porphyrin units. As a result, fluorescence and singlet oxygen quantum yields are close to that of TPP (Table 1). We note however that the presence of the core moiety slightly affects the lower excited state as evidenced from the emission spectrum of 1-3 which are slightly modified: the intensity of the emission sub-band at 717-720 nm increases with respect to that of isolated porphyrin moieties (Figure 2, right). Hence a slight electronic coupling is occurring in the excited state. This reveals that the different moieties in the multiporphyrin assemblies (i.e. conjugated core and porphyrins) do not behave as fully independent units but slightly interact.

The 2PA properties of porphyrin assemblies 1-3 were further examined. Taking advantage of the fluorescence properties, they could be determined in the NIR range by investigating their two-photon excited fluorescence (2PEF), following the experimental protocol described 
by $\mathrm{Xu}$ and $\mathrm{Webb} .^{20}$ Below $740 \mathrm{~nm}$, giant $2 \mathrm{PEF}$ signal increases (and concomitant slight deviation from quadraticity) are observed due to the onset of 1PA resonance (leading to apparent 2PA cross-sections larger than $10^{5} \mathrm{GM}$ for compound 3 at $700 \mathrm{~nm}$ ). We thus restrict further discussion to the spectral range where a fully quadratic dependence of the fluorescence intensity on the excitation power is observed and 2PA responses are fully non-resonant $(\lambda \geq$ $790 \mathrm{~nm}$ ). Quite interestingly, in this spectral range, a marked increase of the 2PA responses compared to that of model TPP (12 GM at $790 \mathrm{~nm}$ ), up to $1360 \mathrm{GM}$ for trimer 3 at the same wavelength is observed (Figure 3). Tripodal triphenylamine cored compounds 1a-b, reveal an enhancement factor of more than 10 while a larger value of 20 is obtained with dumbbell-like fluorene derivative 2 (Table 1). Finally, a 40-fold enhancement is obtained with the extended tripodal compound $\mathbf{3}$.

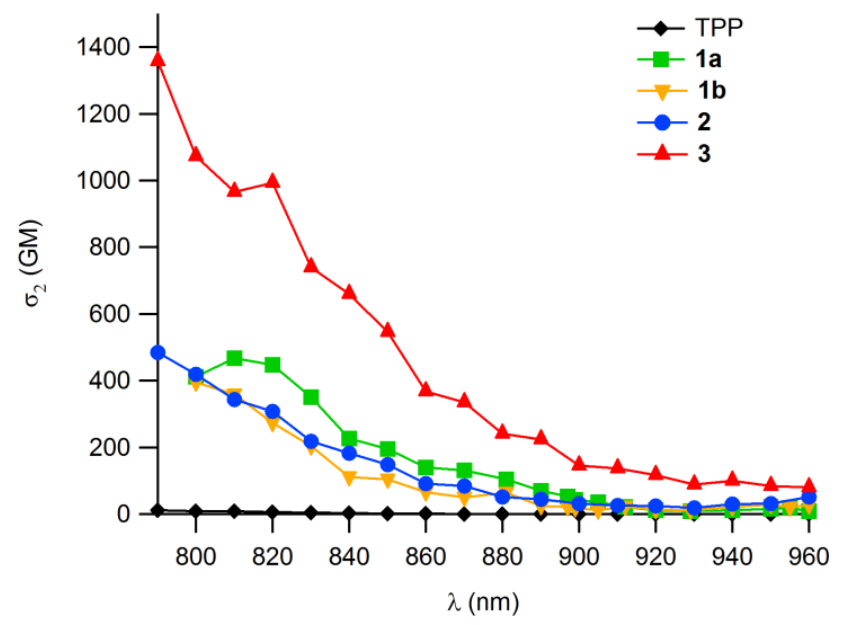

Figure 3. 2PA spectra of $\mathrm{TPP}^{5}$ and "electronically semi-disconnected" porphyrin assemblies.

These striking enhancements provide evidence that the conjugated cores generate higher excited states that are responsible for enhanced 2PA, while allowing fast return (in agreement with Kasha rule) to the lower-excited state responsible for fluorescence (as demonstrated by 2PEF experiments) and singlet oxygen generation. This confirms that the different moieties in 1-3 do not behave as fully independent chromophoric units but slightly interact in the higher excited states. The large (non-resonant) 2PA responses are reminiscent of octupolar (1a-b, 3) or quadrupolar (2) schemes. ${ }^{13}$ In addition, extension of the conjugated branches leads to an increase of the 2PA cross sections and of the enhancement factor of 3 (compared with 1a-b), as expected from an octupolar scheme. ${ }^{13}$ This suggests that the porphyrin end-groups are indeed contributing to the $2 \mathrm{PA}$ response by acting as electro-active end-groups (probably in relation with field rather than resonance effects) in the higher excited states.

In conclusion, by engineering a smooth electronic disconnection between 2PA conjugated systems and peripheral porphyrin emitters/photosensitizers, we have achieved striking (nonresonant) 2PA enhancement in the NIR while retaining excellent fluorescence and photosensitization properties. This "semi-disconnection" strategy, which is different in essence from the strategies based on the full extension of conjugation in porphyrinoids or (supramolecular) assemblies and from FRET based covalent assemblies, opens a promising route for combined two-photon imaging and photodynamic therapy. 


\section{Acknowledgments}

ANR PNANO (07-102) is gratefully acknowledged for postdoctoral fellowships to Y. M. and M. S. CNRS is also acknowledged for a grant to M. C. We wish to thank Vincent Hugues and Marine Baudequin for contribution in 2PEF and synthesis, respectively.

\section{Supplementary data}

Supplementary data (synthetic procedures and spectroscopic data) associated with this article can be found, in the online version, at http://dx.doi.org/***.

\section{References and notes}

1. $\quad$ Dougherty, T. J. J. Clin. Laser Med. Surg. 2002, 20, 3-7.

2. Oleinick, N. L.; Morris, R. L.; Belichenko, I. Photochem. Photobiol. Sci. 2002, 1, 1-21.

3. (a) Bhawalkar, J. D.; Kumar, N. D.; Zhao, C. F.; Prasad, P. N. J. Clin. Laser Med. Surg. 1997, 15, 201-204; (b) Starkey, J. R.; Rebane, A. K.; Drobizhev, M. A.; Meng, F.; Gong, A.; Elliott, A.; McInnerney, K.; Spangler, C. W. Clin. Cancer Res. 2008, 14, 6564-6573; (c) Collins, H. A.; Khurana, M.; Moriyama, E. H.; Mariampillai, A.; Dahlstedt, E.; Balaz, M.; Kuimova, M. K.; Drobizhev, M.; Yang, V. X. D.; Phillips, D.; Rebane, A.; Wilson, B. C.; Anderson, H. L. Nature Photonics 2008, 2, 420-424; (d) Gary-Bobo, M.; Mir, Y.; Rouxel, C.; Brevet, D.; Basile, I.; Maynadier, M.; Vaillant, O.; Mongin, O.; Blanchard-Desce, M.; Morère, A.; Garcia, M.; Durand, J.-O.; Raehm, L. Angew. Chem., Int. Ed. 2011, 50, 11425-11429.

4. Khurana, M.; Collins, H. A.; Karotki, A.; Anderson, H. L.; Cramb, D. T.; Wilson, B. C. Photochem. Photobiol. 2007, 83, 1441-1448.

5. Makarov, N. S.; Drobizhev, M.; Rebane, A. Opt. Express 2008, 16, 4029-4047.

6. $\quad$ Drobizhev, M.; Karotki, A.; Kruk, M.; Mamardashvili, N. Z.; Rebane, A. Chem. Phys. Lett. 2002, 361, 504512.

7. (a) Rath, H.; Sankar, J.; PrabhuRaja, V.; Chandrashekar, T. K.; Nag, A.; Goswami, D. J. Am. Chem. Soc. 2005, 127, 11608-11609; (b) Misra, R.; Kumar, R.; Chandrashekar, T. K.; Nag, A.; Goswami, D. Org. Lett. 2006, 8, 629-631.

8. (a) Ogawa, K.; Ohashi, A.; Kobuke, Y.; Kamada, K.; Ohta, K. J. Am. Chem. Soc. 2003, 125, 13356-13357;

(b) Drobizhev, M.; Stepanenko, Y.; Dzenis, Y.; Karotki, A.; Rebane, A.; Taylor, P. N.; Anderson, H. L. J. Am. Chem. Soc. 2004, 126, 15352-15353; (c) Achelle, S.; Couleaud, P.; Baldeck, P.; Teulade-Fichou, M.P.; Maillard, P. Eur. J. Org. Chem. 2011, 2011, 1271-1279; (d) Hammerer, F.; Achelle, S.; Baldeck, P.; Maillard, P.; Teulade-Fichou, M.-P. J. Phys. Chem. A 2011, 115, 6503-6508.

9. (a) Kim, D. Y.; Ahn, T. K.; Kwon, J. H.; Kim, D.; Ikeue, T.; Aratani, N.; Osuka, A.; Shigeiwa, M.; Maeda, S. J. Phys. Chem. A 2005, 109, 2996-2999; (b) Ahn, T. K.; Kim, K. S.; Kim, D. Y.; Noh, S. B.; Aratani, N.; Ikeda, C.; Osuka, A.; Kim, D. J. Am. Chem. Soc. 2006, 128, 1700-1704; (c) Pawlicki, M.; Morisue, M.; Davis, N. K. S.; McLean, D. G.; Haley, J. E.; Beuerman, E.; Drobizhev, M.; Rebane, A.; Thompson, A. L.; Pascu, S. I.; Accorsi, G.; Armaroli, N.; Anderson, H. L. Chem. Sci. 2012, 3, 1541-1547.

10. (a) Ogawa, K.; Hasegawa, H.; Inaba, Y.; Kobuke, Y.; Inouye, H.; Kanemitsu, Y.; Kohno, E.; Hirano, T.; Ogura, S.-i.; Okura, I. J. Med. Chem. 2006, 49, 2276-2283; (b) Drobizhev, M.; Stepanenko, Y.; Rebane, A.; Wilson, C. J.; Screen, T. E. O.; Anderson, H. L. J. Am. Chem. Soc. 2006, 128, 12432-12433.

11. (a) Dichtel, W. R.; Serin, J. M.; Edder, C.; Frechet, J. M. J.; Matuszewski, M.; Tan, L.-S.; Ohulchanskyy, T. Y.; Prasad, P. N. J. Am. Chem. Soc. 2004, 126, 5380-5381; (b) Oar, M. A.; Serin, J. M.; Dichtel, W. R.; Frechet, J. M. J.; Ohulchanskyy, T. Y.; Prasad, P. N. Chem. Mater. 2005, 17, 2267-2275; (c) Briñas, R. P.; Troxler, T.; Hochstrasser, R. M.; Vinogradov, S. A. J. Am. Chem. Soc. 2005, 127, 11851-11862; (d) Lee, D.-I.; Goodson, T. J. Phys. Chem. B 2006, 110, 25582-25585.

12. (a) In TPP for example, the dihedral angle between the phenyl rings and the macrocycle is more than $60^{\circ}$; (b) Silvers, S. J.; Tulinsky, A. J. Am. Chem. Soc. 1967, 89, 3331-3337.

13. (a) Porrès, L.; Mongin, O.; Katan, C.; Charlot, M.; Pons, T.; Mertz, J.; Blanchard-Desce, M. Org. Lett. 2004, 6, 47-50; (b) Le Droumaguet, C.; Mongin, O.; Werts, M. H. V.; Blanchard-Desce, M. Chem. 
Commun. 2005, 2802-2804; (c) Mongin, O.; Porrès, L.; Charlot, M.; Katan, C.; Blanchard-Desce, M. Chem. Eur. J. 2007, 13, 1481-1498.

14. (a) Lindsey, J. S.; Prathapan, S.; Johnson, T. E.; Wagner, R. W. Tetrahedron 1994, 50, 8941-68; (b) Youngblood, W. J.; Gryko, D. T.; Lammi, R. K.; Bocian, D. F.; Holten, D.; Lindsey, J. S. J. Org. Chem. 2002, 67, 2111-2117.

15. Bansal, R. C.; Eisenbraun, E. J.; Ryba, R. J. Org. Prep. Proced. Int. 1987, 19, 258-60.

16. Tremblay-Morin, J.-P.; Ali, H.; van Lier, J. E. Tetrahedron Lett. 2005, 46, 6999-7002.

17. Barnett, G. H.; Hudson, M. F.; Smith, K. M. J. Chem. Soc., Perkin Trans. 1 1975, 1401-1403.

18. Seybold, P. G.; Gouterman, M. J. Mol. Spectrosc. 1969, 97, 5111-5117.

19. Ganzha, V. A.; Gurinovich, G. P.; Dzhagarov, B. M.; Egorova, G. D.; Sagun, E. I.; Shul'ga, M. J. Appl. Spectrosc. 1989, 50, 402-406.

20. Xu, C.; Webb, W. W. J. Opt. Soc. Am. B 1996, 13, 481-491. 